\title{
LAS GALERAS DEL CORSARIO ALÍ BITCHÍN Y SUS CAMPAÑAS DE SAQUEO EN LAS COSTAS DE ALICANTE Y MURCIA DURANTE LA DÉCADA DE 1630
}

\author{
Francisco Velasco Hernández \\ Universidad de Murcia \\ Consejería de Educación. C.A.R.M.
}

Fecha de recepción: enero 2015

Fecha de aceptación: mayo 2015

\section{INTRODUCCIÓN}

La década de 1630 fue especialmente significativa para el Mediterráneo occidental, sobre todo a partir de 1635 , cuando a las temidas escuadras berberiscas, de galeras y navíos redondos, vino a sumarse la armada francesa con todo su poder de intimidación. Antes ya le habían precedido las flotas inglesa y holandesa, cuyo paso por el Estrecho provocaba toda una oleada de prevenciones y alarmas en los pueblos litorales españoles.

Pero la llegada de esas grandes escuadras cristianas era muy previsible y rara vez, con las excepciones conocidas de Cádiz, Lisboa y La Coruña, solían atacar un espacio portuario concreto. Muy diferente era el comportamiento de las embarcaciones corsarias berberiscas, cuyos objetivos eran claramente predatorios. No despreciaban ningún tipo de presa y tenían especial querencia por el asalto a pequeñas localidades cercanas al mar. Fueron, por tanto, las dueñas y señoras de la navegación costera en el Mediterráneo occidental y solo encontraron cierta rivalidad en la actividad corsaria cristiana practicada por los naturales de Mallorca y los caballeros de Malta ${ }^{1}$.

1. LóPEz NADAL, Gonçal: El corsarisme mallorquí a la Mediterrània Occidental, 1652-1698: un comerç forçat, Barcelona, 1986, y FontenaY, Michel: «Les chevaliers de Malte dans le corso mediterranéen au XVIIe siècle», Las ordenes militares en el Mediterráneo occidental (s. XIII-XVIII), Madrid, 1989, pp. 369-395. 
Como señaló en su momento Fernand Braudel, entre los años de 1580 y 1620 el corso berberisco vivía una segunda edad del oro $^{2}$-que incluso podemos prolongar hasta bien avanzada la segunda mitad del siglo XVII- y cobró un nuevo impulso a partir de la década de 1610 gracias al establecimiento en Argel y Túnez de piratas ingleses y holandeses (John Ward, Simón Danser o Salomo de Veenboer), los cuales introdujeron en esas regencias el arte de construir y gobernar naves atlánticas -los también llamados «navíos redondos»-, capaces, no solo de actuar en el Mediterráneo, sino, sobre todo, en el océano ${ }^{3}$.

Poco a poco, los navíos «redondos» o de alto bordo se fueron imponiendo en la navegación corsaria, tanto en el Mediterráneo occidental como en el área del estrecho de Gibraltar, formando poderosas escuadras, que en muchas ocasiones superaban las treinta o cuarenta unidades. Los arráeces berberiscos fueron desechando así sus viejas galeotas, poco aptas para adentrarse en el Atlántico, y reaprovecharon su madera, jarcia y armamento en la construcción de estos nuevos barcos más poderosos.

Sin embargo, el ascenso político de un nuevo renegado cristiano en Argel, el veneciano Niccolo Piccini, bautizado como Alí Bitchín, insufló nuevos bríos en las décadas de 1620 a 1640 a la marina de remo argelina, auxiliada en muchas ocasiones por las galeras o galeotas de Bizerta (Túnez). Serán estas galeras las que siembren el terror en las costas del Sureste durante las décadas de 1630 y 1640, creando una espiral de violencia similar a la de los últimos años del siglo XVI.

El ámbito del Sureste español vivía también un momento de prosperidad gracias al desarrollo comercial de los puertos de Alicante y Cartagena, al que no eran ajenos los corsarios berberiscos. La constante circulación por sus aguas de embarcaciones mercantes cristianas y la salida de productos propios (barrilla, sosa, esparto, alumbres, sal, jabón) y del interior castellano y valenciano (lana, seda, paños, trigo, etc.) generaban un intenso tráfico mercantil que sobrevivió a lo largo del siglo XVII, a pesar de la fuerte presión fiscal, de las guerras y del acoso de la piratería ${ }^{4}$. De ahí que fuesen objeto de un constante acoso por parte de los marinos magrebíes, al igual que sus pueblos costeros, que se sentían constantemente amenazados, como ocurrió en esta difícil década de 1630 .

El artículo que hoy presentamos se centra, por tanto, en la actuación de una parte de la armada berberisca, las naves de remo, cuyo poder devastador en las costas mediterráneas -y en las de Alicante y Murcia en especial- era superior a sus navíos de alto bordo, más letales en la navegación atlántica. Sus objetivos eran bien definidos: el

2. Braudel, Fernand: El Mediterráneo y el mundo mediterráneo en la época de Felipe II, Madrid, 1980, t. II, págs, 304-311.

3. Tinniswood, Adrian: Pirates of Barbary: corsairs, conquests, and captivity in the seventeenth-century Mediterranean, New Cork, 2010, pp. 51-57; sobre la actividad estos piratas en las costas de Alicante y Murcia: Velasco HernÁNDEZ, Francisco: «Corsarios y piratas ingleses y holandeses en el Sureste español durante el reinado de Felipe III (1598-1621)», Investigaciones Históricas, n. 32 (2012), pp. 95-116.

4. Velasco Hernández, Francisco: «El auge económico de Cartagena y la revitalización del Sureste español en los siglos XVI y XVII», Hispania, LXV/2, n. ${ }^{o} 220$ (2005), pp. 485-514 
abordaje de embarcaciones y el asalto de los pueblos costeros del Sureste, como bien hemos podido comprobar en la rica información que aportan la sección de Guerra y Marina del Archivo General de Simancas, la del Consejo de Aragón del Archivo de la Corona de Aragón y las actas capitulares de los archivos murcianos y alicantinos; hecho que contrasta con la escasa bibliografía existente sobre el tema en el ámbito del Sureste, pues la mayor parte de lo publicado, o bien corresponde al siglo XVI o al XVIII, aunque con alguna escasa excepción ${ }^{6}$.

\section{ALÍ BITCHÍN Y LA OFENSIVA CORSARIA SOBRE EL SURESTE DE MEDIADOS DEL XVII}

Sin duda, el personaje más influyente en las regencias berberiscas durante esta década de 1630 era Alí Bitchín. Sus orígenes son algo oscuros, pues realmente existen pocas noticias concretas sobre su vida y en muchos casos lo que se conoce de él es en gran parte anecdótico. Las dos mejores descripciones sobre su persona, bienes y actividad fueron escritas por dos cautivos cristianos que le sirvieron como esclavos entre 1637 y 1641 y que consiguieron escaparse o redimirse ${ }^{7}$. Ambos coinciden en que Bitchín era por esa época una figura inmensamente poderosa en Argel, tan influyente, que los extranjeros europeos lo consideraban como jefe de Estado de facto, por encima del pachá o bey, e incluso del Agha, que mandaba sobre el cuerpo de los jenízaros.

Al parecer era hijo adoptivo del gran Morato Arráez, el renegado albanés que fue jefe de la taifa de arráeces de Argel desde 1580 a 1605. Él era también un renegado, aunque de origen veneciano, que, según la tradición argelina, había nacido en un pueblo llamado Piccini - de ahí su nombre-, pueblo que en la actualidad no existe. Como otros nombres de corsarios argelinos, se le denomina de diferentes maneras según las fuentes: Alí Bitshnin, Alí Pizilini, Alí Pichellin, Alí Pichinin y Alí Pegelin.

\footnotetext{
5. Los archivos referidos son los de Cartagena, Murcia, Lorca y Mazarrón. La documentación municipal alicantina, limitada casi exclusivamente a las marinas de Orihuela y Elche (la de Alicante ha desaparecido), fue trabajada en su día por ReQuena Amoraga, Francisco: El corso turco-berberisco en la gobernación de Orihuela (siglos XVI-XVII), Elche, 2001, cuyo trabajo hemos aprovechado.

6. En lo que se refiere a la costa alicantina: PArdo Molero, Juan Francisco: La defensa del imperio. Carlos V, Valencia y el Mediterráneo, Valencia, 2001; GARcía MartíneZ, Sebastián: Bandolerismo, piratería y control de moriscos en Valencia durante el reinado de Felipe II, Valencia, 1977; y Pradells NADAL, Jesús: «La defensa de las costas valencianas en el siglo XVIII ante el corsarismo y la piratería norteafricanas», El Mediterráneo, un mar de piratas y corsarios, Santa Pola, 2002. En cuanto a la murciana, Ruiz IbÁÑ̃z, José Javier \& Montojo Montojo, Vicente: Entre el lucro y la defensa: las relaciones entre la monarquía y la sociedad mercantil cartagenera (comerciantes y corsarios en el siglo XVII), Murcia, 1998.

7. Knight, Francis: A Relation of Seaven Yeares Slaverie Under the Turks of Argeire, London, 1640; y D'Aranda, Emmanuel: Relation de la captivité et liberté du sieur Emanuel D'Aranda, Bruselas, 1662.
} 
En 1619 ya debía de ser una persona importante, pues era dueño de sesenta y tres esclavos cristianos. En 1622 construyó una mezquita en Argel de estilo bizantino-turco (la mezquita de Alí Bitchin), que aún perdura en la actualidad. Por esos años se casa con la hija del rey de Cuco, jefe de una tribu cabila casi independiente. Esta tribu le proporciona su guardia pretoriana ${ }^{8}$. En esa década de 1620 fue nombrado capitán de la mar o jefe del gremio de arráeces de Argel. Como jefe de la taifat al-rä̈s, se las arregló para mantener un difícil equilibrio entre los intereses de los corsarios, los de la clase mercantil que financiaba sus incursiones y los del cuerpo de jenízaros. También supo mantener bajo su control las fuerzas navales de Túnez y Argel, las cuales comandaba personalmente en muchas de sus expediciones.

Sus riquezas eran inmensas, como nos describe D'Aranda. Poseía un palacio en la ciudad, una casa de campo, varias galeras o galeotas y miles de esclavos. Una parte de ellos residía en un conjunto de edificios cerca de su palacio y de su mezquita, el denominado «baño», en cuyo interior había una iglesia y una taberna, dirigida por sus esclavos y frecuentada también por los jenízaros turcos.

Además de sus razias anuales contra las costas italianas y españolas -de las que aquí damos cuenta, aunque limitadas al Sureste-, en 1637 atacó las instalaciones pesqueras francesas en el norte de África, el llamado «Bastion de France» (cerca de Bona), capturando a 317 personas, incluido el gobernador ${ }^{9}$. Ese año fue su momento cumbre.

En 1638 sufrió la tremenda derrota de Valona ante la escuadra veneciana, que le hizo perder 16 galeras o galeotas, además de unos 1.500 soldados y unos 3.500 esclavos cristianos. Había sido obligado por el Gran Señor a intervenir como vasallo suyo contra Venecia y no sólo no fue premiado, sino que tampoco obtuvo ningún tipo de indemnización por los turcos. Esta humillación enrareció las relaciones de la taifa de arráeces de Argel y su divan (o gobierno de la ciudad) con el sultán de Estambul y el bey o gobernador turco de la regencia, lo que supuso un punto de inflexión en el vasallaje que los argelinos mantenían con respecto a la Sublime Puerta desde los tiempos de Barbarroja.

La deseada autonomía del Argel capitaneado por Bitchín chocaría pronto con los intereses particulares del sultán Ibrahim I, que había planeado en 1644 un ataque contra Malta, para el que contaba con el auxilio de la armada berberisca. La defección de sus vasallos de Argel y Túnez, que desoyeron el mandato, le obligaría a renunciar finalmente al ataque. La ira del Gran Turco pronto se precipitaría sobre Argel y en apenas unos meses se iba a producir un intento de apresar a Bitchín y a los principales instigadores de la defección, una revuelta popular que encumbraría al jefe corsario como gobernador, un motín del cuerpo de jenízaros que le obligaría a huir y a refugiarse en el reino de Cuco, la vuelta triunfal de éste y la llegada en 1645 de un nuevo bey enviado por el sultán, una vez pacificada la ciudad ${ }^{10}$. Pero poco tiempo después, Alí Bitchín

8. Belhamissi, Moulay: Historie de la marine algerienne (1516-1830), Alger, 1986, p. 85.

9. Wolf, John B.: The Barbary Coast. Algeria under the Turks, New York-London, 1979, p. 209.

10. Tinniswood, Adrian: Pirates of Barbary..., p. 189. 
moría de forma misteriosa. Entre los argelinos se extendió la sospecha de que había sido vilmente envenenado. El funeral, digno de un rey, que el pueblo argelino le brindó, puso de manifiesto la enorme fractura que ya existía entre las regencias berberiscas y la Sublime Puerta, cuyo proceso de independencia respecto a esta última se irá acentuando a lo largo del siglo XVII ${ }^{11}$.

\section{LOS PRIMEROS AÑOS (1631-1634)}

Las naves de remo comandadas por Alí Bitchín fueron las responsables de la mayor parte de las trágicas campañas emprendidas contra el Sureste de la década de 1630, como bien certifican algunos de los esclavos cristianos huidos de sus naves e incluso el propio sacerdote de Benisa, Mosén Pedro Cabrera, que se entrevistó personalmente con Bitchín en su magnífica galera unos días después del asalto a Calpe.

Estas escuadras de remo de Argel y Túnez eran muy poderosas e incluían tanto galeras como galeotas. La diferencia entre ambas la marcaba el número de bancos y de remeros por banco: de más de 24 ó 25 bancos se consideraba galera y de menos, galeota; la galera llevaba tres remeros por banco y la galeota dos. En la década de 1630, Argel llegó a contar con unas 9 galeras o galeotas ${ }^{12}$ y Túnez con $\operatorname{cinco}^{13}$. Cada una de estas naves podía llevar a bordo 100 o 120 soldados (tucos, berberiscos o renegados), además de los galeotes o remeros y de los marineros - normalmente cristianos- que se encargaban de gobernar la nave.

Ya a mediados de agosto de 1630 fue vista esta escuadra mixta de 13 galeras en la costa de levante de Cartagena. Como la amenaza era de envergadura, se tocó a rebato en la ciudad y se levantó a todos los vecinos en armas. También se colocaron postas en diversos puntos, se mandó un laúd a reconocer la costa y se distribuyó pólvora, armas y municiones en todos los baluartes. Todos los vecinos del campo fueron obligados a recogerse entre las murallas de la ciudad. Pero al día siguiente la alarma se tornó en terror cuando aparecieron otros 20 navíos redondos corsarios en esa misma zona, donde habían dado caza a una saetía mercante y desembarcado a más de un centenar de soldados en tierra. Ante tal peligro, fue necesario pedir el socorro de dos compañías de milicia de Murcia y una de Fuente Álamo. Afortunadamente, dos días después, las naves enemigas desaparecieron de la $\operatorname{costa}^{14}$. Fue la carta de presentación de esta nueva década, terrible en cuanto a presión corsaria.

Hasta finales de octubre de 1631 no volvieron a aparecer más galeotas. Concretamente, el día 23 de ese mes fueron descubiertas cuatro naves de remo en Calblanque (Cartagena) y provocaron de nuevo una cadena de prevenciones. En este caso no parecía un peligro importante, por lo que las autoridades se limitaron a vigilar el movimiento de las embarcaciones enemigas desde las diferentes atalayas de la costa

\footnotetext{
11. Wolf, John B.: The Barbary Coast... pp. 148-149.

12. Belhamissi, Moulay: Historie de la marine..., p. 63.

13. Sebag, Paul: Tunis au XVIIe siècle. Une cité barbaresque au temps de la course, Paris, 1989, p. 96.

14. Archivo Municipal de Cartagena (A.M.C.), Ac. caps. 17, 18 y 20-VIII-1630.
} 
y a mandar un laúd para que averiguara si desembarcaban o quedaban fondeadas en el mar. Las galeotas se marcharon pronto, puesto que es posible que supieran de la próxima llegada a Cartagena de cuatro galeras de Génova procedentes de Denia ${ }^{15}$. Pero no debieron de irse muy lejos, toda vez que a finales de noviembre fueron de nuevo vistas en las inmediaciones de Mazarrón camino de sus bases invernales en Berbería ${ }^{16}$.

El año de 1632 fue bastante tranquilo, ya que apenas fueron avistadas naves de remos en las costas murcianas y alicantinas. En esa campaña corsaria debieron de ser otros los destinos elegidos: casi con toda seguridad las costas italianas del sur y las de Baleares y Cataluña. Precisamente una noticia llegada a Cartagena el 2 de septiembre confirmó que cuatro galeotas gruesas de moros habían saqueado un pueblo de Cataluña, sin que especificara de cuál se trataba y tampoco si eran las naves de Argel o las de Túnez. Tres meses antes había llegado otro aviso del virrey de Valencia dando cuenta de la salida de cuatro galeotas de Argel con intención de tomar el pueblo alicantino de Calpe, especie de premonición de lo que luego ocurriría cinco años después ${ }^{17}$.

La campaña corsaria de 1633 sí tuvo como objetivo las costas del Sureste. Pronto aparecieron galeotas en sus mares. Así, en una fecha tan temprana como marzo, fueron descubiertas tres naves de remos en la isla de Santa Pola. La casualidad hizo que se encontraran en el puerto de Cartagena las siete galeras de la escuadra de Génova al mando de Juanetín Doria, que no tardó en pedir refuerzos de infantería al concejo para salir tras ellas. Los capitulares ordenaron que se embarcara una compañía de voluntarios y que el botín obtenido se repartiera de la misma forma que se hacía en las galeras $^{18}$.

En el mes de mayo ya eran cuatro las galeotas que merodeaban por la costa. Un aviso procedente de Guardamar confirmó que había cuatro de estas naves sobre Calpe a mediados de ese mes, sin que se supiera a ciencia cierta su intención ${ }^{19}$. Diez días antes había llegado a Cartagena una comunicación de Alicante informando de que en Formentera se encontraban despalmando tres galeotas y un bergantín corsario preparados para caer sobre estos mares ${ }^{20}$. No andaban muy desacertadas estas noticias, puesto que a finales de ese mes quedaron estacionadas las cuatro galeotas en el cabo de Cope, lugar donde dos de sus tripulantes (un cautivo y un renegado) pudieron saltar a tierra y huir hasta Mazarrón. En esta villa murciana comunicaron que las naves argelinas habían capturado tres saetías francesas y llevaban propósito de permanecer en estas aguas durante un $\mathrm{mes}^{21}$.

15. A.M.C. Ac. caps. 23 y 24-X-1631.

16. Archivo Municipal de Mazarrón (A.M.Mz.), Ac. cap. 25-XI-1631.

17. A.M.C. Ac. cap. 2-IX-1632 y Archivo Municipal de Murcia (A.M.M.), Ac. cap. 19-V-1632.

18. A.M.C. Ac. cap. 19-III-1633.

19. A.M.Mz. Ac. cap. 15-V-1633.

20. A.M.C. Ac. cap. 5-V-1633.

21. A.M.C. Ac. cap. $27-\mathrm{V}-1633$. 
El cautivo cristiano fue remitido a Murcia, donde fue interrogado por el corregidor. Lo más curioso es que declaró que los guardas de una torre costera de Alicante tenían amistad con los corsarios, pues hablando con ellos les dijeron «que si antes un poco ubieran llegado allí tomaran una saetía... y que las galeras de Génoba abian pasado a España, y que por cumplimiento, la jente de la torre les tiraron treinta mosquetaços sin bala porque el castillo creyera [que] peleaban, y los turcos decían esta es la torre de los amigos». Describía esa torre como una que poseía un baluarte o revellín abajo, un castillo grande arriba y otro pequeño, y se atrevía a decir que posiblemente era la de Villajoyosa ${ }^{22}$. Esta información fue remitida con toda urgencia por el corregidor al marqués de los Vélez, virrey de Valencia, para que investigara el hecho y castigara a los responsables.

A estas cuatro galeras se unieron en el mes de junio 40 navíos redondos corsarios, que fueron vistos en Alicante y Santa Pola el día 17. Dos días después, apareció esta poderosa fuerza a la vista del puerto de Cartagena provocando un fortísimo rebato, que puso en pie a todos los vecinos de la ciudad y comarcas próximas ${ }^{23}$. De Murcia llegaron las dos tropas de la milicia como refuerzo y aprestaron el resto de compañías para salir hacia Cartagena al menor aviso. Afortunadamente, el día 21 siguieron camino hacia poniente, sin que resultara ningún daño para los vecinos.

La temporada de 1634 fue de nuevo otro año tranquilo, a pesar de haberse descubierto a principios de mayo 40 navíos de guerra holandeses cerca de Cartagena. Solo recalaron una vez las galeotas berberiscas en esta costa, concretamente, en la marina de Lorca, donde, como sabemos, estaban sus guaridas de Cope y Calabardina. El concejo de Mazarrón insistía en que eran las mismas galeotas que el año anterior habían llevado a cabo muchos robos y presas, tanto por mar como por tierra, por lo que previno a toda su gente de guerra para cualquier eventualidad ${ }^{24}$. Pero, casi a la misma vez, llegaron a Cartagena dos galeazas de la escuadra del duque de Florencia, cuyo poder intimidatorio debió de alejar a los corsarios de estos mares, pues ya no se volvió a saber de ellos en todo el resto del año ${ }^{25}$.

\section{LA CAMPAÑA DE 1635 Y LA DESTRUCCIÓN DE LAS PRIMERAS TORRES}

Como de costumbre, poco antes del estío comenzaba el trasiego anual de las galeotas berberiscas por las costas españolas e italianas, una vez concluidas las labores de carenado y puesta a punto llevadas a cabo en el invierno magrebí. A comienzos del verano de 1635 ya habían sido divisadas en los mares del Sureste algunas de estas escuadras ejerciendo su tradicional labor predatoria sobre las naves mercantes cris-

22. Archivo General de Simancas (A.G.S.), G.M., leg. ${ }^{\circ} 1.089$.

23. A.M.C. Ac. cap. 19 y 20-VI-1633 y A.M.M. Ac. cap. 19, 20 y 21-VI-1633.

24. A.M.Mz. Ac. cap. 21-V-1634.

25. A.M.C. Ac. cap. 20-V-1634. 
tianas $^{26}$. En la madrugada del 22 de junio, fueron descubiertas desde las puntas del puerto de Cartagena seis galeotas corsarias en persecución de siete saetías mercantes, a las cuales dieron caza en las calas y playas de Calnegre, Cope y Calabardina, en la marina de Lorca. Aunque las siete saetías fueron hundidas o capturadas, algunos de sus marineros consiguieron salvarse y dar la noticia en Mazarrón ${ }^{27}$. Por un informe enviado posteriormente por el corregidor murciano al Consejo de Guerra, se sabe que esas saetías habían salido de Cartagena el mismo día formando un convoy y que, tras ser abordadas, fueron apresadas y enviadas con su tripulación y mercancías a $\operatorname{Argel}^{28}$. Tres de las saetías eran catalanas, dos francesas y una de Alicante. Fue un espectacular golpe de mano, que tuvo una enorme resonancia en las costas del Sureste.

En los días siguientes, las galeotas navegaron entre el cabo de Cope y la isla Grosa, donde capturaron a los tripulantes de una barca de pescadores de Cartagena. No mucho tiempo después, atraparon un barco longo que había salido de Cartagena y que llevaba a bordo a un noble genovés y a su hija monja. Los marineros de ese barco intentaron saltar a tierra, pero fueron acribillados a balazos por los corsarios, que los desnudaron y dejaron flotando en el mar $^{29}$.

Como era de esperar, la presencia de esta escuadrilla de galeotas provocó los consiguientes rebatos en las localidades de la costa. Tanto Cartagena, como Mazarrón o Lorca pusieron en máxima alerta sus tropas, recogieron la gente del campo y reforzaron todos sus baluartes e incluso se avisó a Murcia para que preparara un posible socorro. Las localidades costeras de la gobernación de Orihuela debieron de tomar las mismas medidas, como se deduce del nuevo reparto de pólvora efectuado entre los baluartes de la ciudad Alicante en ese mes de junio ${ }^{30}$.

El 26 de junio, uno de los guardas de Calnegre confirmó que las citadas galeotas se habían quedado fondeadas en la cala del Hornillo, próxima a Águilas. Los regidores de Lorca, ajenos a lo que después ocurriría, tomaron como medidas de precaución prevenir a la gente de guerra para un posible socorro a Mazarrón e instalar las postas acostumbradas para comunicar con la citada villa. Pero no sería Mazarrón el objetivo inmediato de los corsarios, sino otro mucho más sencillo: la torre de Águilas.

Esta torre se hallaba enclavada en mitad de la marina de Lorca, un extenso espacio deshabitado en el que no había arraigado ningún núcleo poblacional estable. De hecho, desde Vera hasta Mazarrón se describía un largo desierto costero, de unos 85 kilómetros, que era «tierra de nadie» y en el que los corsarios argelinos actuaban con toda impunidad. La indefensión de este tramo costero movió a Felipe II a ordenar en 1578 la construcción de dos torres similares, las de Águilas y Terreros Blancos, al objeto de enlazar la frontera sur del reino de Murcia con la del reino de Granada, siguiendo

26. Ruiz IbÁÑez, José Javier \& Montojo Montojo, Vicente: Entre el lucro... pp. 175-176.

27. A.M.Mz., Ac. cap. 22-VI-1635 y A.M.L., Ac. cap. 26-VI-1635.

28. A.G.S., G.M., leg. ${ }^{\circ} 1.178$.

29. A.G.S., G.M., leg. ${ }^{\circ} 1.178$.

30. Requena Amoraga, Francisco: El corso turco-berberisco..., p. 350. 
lo proyectado por el ingeniero real Juan Bautista Antonelli y el duque Vespasiano de Gonzaga. Ambas torres estaban terminadas en $1579^{31}$.

En el citado cabildo de 26 de junio, antes de que acabara la sesión, llegó la noticia de que «los moros que estauan en la marina desta ciudad an saqueado la torre de las Águilas... [y] hasta aora no se sabe cosa çierta por no aver requeridor dellas en esta ciudad... $\rangle^{32}$. El concejo lorquino decidió enviar de inmediato al mantenedor de la torre Francisco Ros (junto con otros soldados) a reconocer los daños causados en ella por los corsarios. En la noche del 29 ya estaba de vuelta y expuso ante el cabildo, reunido en sesión extraordinaria, los estragos que habían producido los «más de 700 turcos» desembarcados: «la torre estaba saqueada y abían derribado della el rebellín de la plaza de armas y hecho otros daños, como fueron llevarse la puerta prinçipal y quemado las escalas, y de las personas que Su Ex. ${ }^{a}$ tenía puestas para guarda de la dicha torre no pareçió ninguna ...» $\gg^{33}$. Señalaba también que era muy necesario reparar el daño sin dilación alguna, toda vez que la torre de Águilas era el mejor seguro de la marina de Lorca y el punto principal desde donde se avisaba del peligro corsario a otros lugares de la $\operatorname{costa}^{34}$.

El concejo decidió rápidamente dar cuenta de lo sucedido al rey y al marqués de los Vélez, a cuyo cargo estaba el mantenimiento y reparación de esta fortaleza, solicitándole que acudiera con lo necesario para reedificarla y reponer su artillería. Sin más demora, se envió un emisario a Mula con una carta para la marquesa de los Vélez representándole todo lo sucedido y la necesidad de actuar con la máxima diligencia para evitar daños irreparables en aquella costa. Pero la marquesa, sin la aquiescencia de su marido (que se encontraba en Valencia ejerciendo el cargo de virrey), no tomó ninguna decisión que le pudiera comprometer; y lo mismo ocurrió en los meses siguientes, a pesar de que se le insistió varias veces sobre ello.

Dos semanas más tarde, pudo comprobarse que las galeotas se habían ido, por lo que Mazarrón levantó su cuerpo de guardia y lo mismo hicieron en Cartagena y en Lorca $^{35}$. Es muy posible que estas galeotas pusieran rumbo a levante para encontrarse con las cinco galeras de Bizerta que días atrás habían sido vistas en las costas de Cataluña. De hecho se llegó a pedir a Lorca y Cartagena que hicieran una escolta con atajadores y barcas a dos galeras de España que iban desde Almería a Barcelona, para evitar que se encontraran con los navíos berberiscos ${ }^{36}$.

Las embarcaciones corsarias no volvieron hasta primeros de septiembre. El día 5 se recibió un aviso en Cartagena comunicando la presencia de cinco galeotas, una fragata y tres bergantines de moros en el cabo de Cope, los cuales permanecieron fon-

31. Velasco HernÁndez, Francisco: «Cinco torres para un reino: Los proyectos de Felipe II para fortificar la costa murciana (1570-1580)», Cartagena Histórica, n. ${ }^{\circ} 39$ (2013), pp. 18-20.

32. Archivo Municipal de Lorca (A.M.L.) Ac. Caps. 1634-36, cab. ${ }^{\circ}$ 26-6-1635.

33. A.M.L. Ac. cap. 30-6-1635. También se relatan estos hechos en A.G.S., G.A., leg. ${ }^{\circ} 1.147$.

34. A.M.L. Ac. cap. 30-6-1635.

35. A.M.Mz. Ac. cap. 7-VII-1635.

36. A.M.L. Ac. cap. 10-VII-1635 y A.M.C. Ac. cap. 11-VII-1635. 
deados en esa zona varias semanas. El corregidor murciano informó posteriormente al Consejo de Guerra que éstas habían capturado tres fragatas que venían de Vera cargadas de trigo y cebada para la plazas de Orán, y aunque sus marineros saltaron a tierra, los corsarios los emboscaron y cautivaron.

La presión llegó hasta tal punto que, en los concejos de Cartagena y Lorca, surgieron voces pidiendo la intervención de las milicias urbanas en la costa. En Cartagena se hizo la propuesta de salir con una tropa de 100 arcabuceros, que finalmente no prosperó. Pero en Lorca su alcalde mayor tomó la determinación el 28 de septiembre de salir a repeler los desembarcos de esas galeotas, que desde hacía unas semanas atemorizaban a toda su marina, «haciendo muchas presas de navíos, galeras, saetías y otros bajeles, cautibando muchos vecinos de los lugares desta comarca, los quales ansimismo auían saqueado sus torres y dado muestras de arruinarlas de nuebo» ${ }^{37}$. Para ello, organizó una fuerza de más de 500 infantes, que intentaron hacerles alguna emboscada agazapados cerca de la costa, pero su intento fue en vano, a pesar de que aguardaron dos días esperándolas.

El balance de la campaña corsaria de 1635 había sido aterrador, tal como señalaba el corregidor Juan Gutiérrez Tello: «Y goçaron de tanta seguridad todo el dicho verano, que no les ofendió jamás ningún nauío ni galera. Y quando les faltaba vastimento, enbiavan por él a Argel, y se lo traían con la misma seguridad. Muchos daños pueden suçeder por estar aquel puerto [de Cartagena] sin navíos... Y lo peor es que oy, que está toda cargada por estos rumores, podrán volver a la ciudad y matar la gente della, y asolarla con sus mismas armas» ${ }^{38}$.

\section{EL RAID DE 1636 Y EL ASALTO A LAS TORRES ALICANTINAS DEL DISTRITO DE ORIHUELA}

La llegada del buen tiempo en la mar se traducía en temor y recelo para los habitantes de las poblaciones litorales del Sureste. Ya el día 5 de mayo habían sido descubiertos varios navíos de remo en la localidad almeriense de Adra. Se trataba de ocho galeras, siete argelinas y una probablemente tunecina. A primero de junio, dos de esas galeotas fueron divisadas desde Mazarrón camino de su guarida en Cope, donde solían fondear y aprovisionarse de agua ${ }^{39}$. La presencia de la armada francesa en estas aguas a mediados de junio debió de alejarles de la zona por un tiempo y es muy posible que retornaran a sus bases. Pero en el mes de agosto volvieron de nuevo a la marina de Lorca con el propósito de acabar definitivamente con la torre de Águilas.

Tras el asalto de junio de 1635, el concejo lorquino había enviado a la torre otro alcaide y dos soldados, pero se encontraban tan desprotegidos que en el mes abril siguiente «se a vuelto uno diziendo que la dicha torre está bendida y que es ynpusible poderla defender ni conserbar... porque debiendo por lo menos aver para ello dos o

37. A.M.L. Ac. cap. 28-9-1635.

38. A.G.S., G.M., leg. ${ }^{\circ} 1.178$.

39. A.M.Mz. Ac. cap. 1-VI-1636. 
tres pieças de artillería no ay más que dos mosquetes y un arcabuz, y que los otros dos soldados que quedan, recelosos de que los an de cautibar... se tratan de venir, con que la dicha marina quedará sin defensa» ${ }^{40}$. En ese cabildo se decidió escribir de nuevo a la marquesa para que con el dinero procedido del arbitrio sobre el ganado se comprara, al menos, una pieza de artillería. Pero la marquesa no hizo nada. Los que sí hicieron efecto fueron los «400 turcos de pelea» que el 16 de agosto de 1636 desembarcaron de dos galeotas y la batieron de forma definitiva, cautivando una vez más a sus tres soldados ${ }^{41}$.

No debieron de permanecer allí mucho tiempo, pues, como informó un turco renegado - que había huido de ellas-, partieron hacia el Grao de Valencia a juntarse con las otras cuatro galeotas de su escuadra, desde donde marcharon rumbo a Argel. En el puerto africano debieron despalmar, acopiar provisiones y preparar una nueva razia, que tendría una vez más como objetivo las costas del Sureste español.

A pesar de ser ya una época peligrosa para la navegación, el 13 de octubre pasó a la vista del puerto de Cartagena una galera cuyo destino era reunirse con otras que estaban fondeadas en Cope. Las características de esta embarcación se conocieron gracias a la confesión de un renegado que huyó de ella y que confirmó que se trataba de una galera de 26 bancos y 360 soldados, la cual había recogido a su paso cuatro esclavos moros fugitivos ${ }^{42}$. El gran tamaño de esa nave y la numerosa tropa que llevaba a bordo nos hace pensar que posiblemente se trataba de la galera capitana de Alí Bitchín. Tal como se esperaba, al día siguiente, las guardas de Mazarrón confirmaron que eran seis galeras reforzadas las que se encontraban en Cope, o, lo que es lo mismo, la escuadra de remo de Argel casi al completo ${ }^{43}$.

En cualquier caso, estas galeras permanecieron hasta el mes de noviembre navegando en las costas de Alicante y Murcia. El 9 de noviembre una guarda de Cartagena las había descubierto en la isla Grosa, desde donde salieron tras una saetía mercante, a la que atraparon. En los días siguientes se les incorporó otra galeota y un bergantín. Con esta fuerza naval llevarían a cabo el ataque a las torres del sur de la gobernación de Orihuela.

Las tres torres alicantinas protagonistas de los hechos de 1636 (Torrevieja, Cabo Roig y La Horadada) fueron construidas en diferentes épocas, que van desde la etapa del duque de Maqueda hasta la que finaliza en los años postreros del siglo XVI. Con estos tres baluartes -a los que habría que añadir el del cabo Cervera y la Torre Nueva de las Salinas- se cerraba el flanco sur del sistema defensivo del reino de Valencia, al tiempo que se le conectaba, una vez terminada la torre del Pinatar en 1602, con la línea de atalayas del reino murciano ${ }^{44}$.

40. A.M.L. Ac. Caps. 1634-36, cab. $^{\circ} 4-4-1636$.

41. A.G.S., G.M., leg. ${ }^{\circ} 1.171,1.172$ y 1.174.

42. A.M.C. Ac. cap. 13-X-1636.

43. A.M.Mz. Ac. Cap. 14-X-1636.

44. Sobre la construcción de estas torres, véase: REQuena Amoraga, Francisco: La defensa de las costas valencianas en la época de los Austrias, Elche, 1997, pp. 109-117, y CÁMARA MuÑoz, Alicia: «Las torres del litoral en el reinado de Felipe II: una arquitectura para la defensa del territorio (y II), Espacio, 
Según el informe del capitán Pedro Liminiana Hurtado, que acudió de inmediato al socorro de la costa, cuatro galeotas corsarias con numerosa infantería atacaron sucesivamente las torres de Torrevieja, Cabo Roig y La Horadada, aunque en este último caso no pudieron lograr su objetivo. Al parecer, unos 500 soldados desembarcaron el día 10 de noviembre frente a la Torre Vieja y la asaltaron y quemaron, capturando a sus cuatro guardas. Después de esto, la tripulación de dos de ellas bajó a tierra e inició una razia por el campo inmediato, mientras que la de las otras dos -unos 200 hombresatacaron la torre de Cabo Roig, que fue igualmente saqueada, sus guardas capturados y todo el edificio incendiado. Reunidas de nuevo las cuatro galeotas, se dirigieron a continuación hacia la torre de La Horadada, que por un momento pudo correr la misma suerte, pero la llegada de las tropas oriolanas al mando de Marco Antonio Pascual, subrogado del gobernador, impidió que los corsarios pudieran conseguir su objetivo ${ }^{45}$.

La noticia corrió como la pólvora por toda la costa de levante y poniente. En Murcia se puso rápidamente en guardia a las compañías de la milicia y de las parroquias para que a la primera llamada acudiesen a socorrer los lugares amenazados ${ }^{46}$. En Cartagena se tomaron medidas similares, como también en Mazarrón y Lorca; por último, se informó a la ciudad de Vera para que estuviera prevenida ${ }^{47}$.

A pesar del daño hecho, no se les pudo oponer ningún tipo de resistencia; al contrario, las galeotas permanecieron impunes en su guarida de la isla Grosa hasta el día 13 de noviembre, manteniendo en estado de máxima alarma a las localidades de la vega baja del Segura y de la costa murciana de levante. Sólo hasta que pudo comprobarse que estas naves se habían marchado definitivamente, se inició la evaluación de los daños en las torres asaltadas. El espectáculo era ciertamente desolador: en Cabo Roig, las puertas de hierro de la torre y del cortijo habían sido arrancadas de sus marcos y destrozadas. Además, el incendio de ambos edificios había destruido en parte las caballerizas, las estancias de los atajadores y el aposento del capitán, junto a otros desperfectos y robos (las armas y una pequeña pieza de artillería). Tampoco en la Torre Vieja el panorama era muy halagüeño, repitiéndose lo visto anteriormente en Cabo Roig ${ }^{48}$. Sin embargo, tanto la torre de la Horadada como la del cabo Cervera habían resultado intactas, por lo que los daños, dentro de lo malo, pudieron ser minimizados.

Con la destrucción de ambas torres debió de darse por finalizada la campaña corsaria de 1636. El concejo de Mazarrón, en su reunión de 16 de noviembre, habla de estas galeotas pero sin concretar el punto exacto en el que se hallaban ${ }^{49}$. De todas formas,

Tiempo y Forma, serie VII, t. 4 (1991), pp. 66-74. La torre de cabo Cervera era de origen medieval y ya existe constancia de ella en los siglos XIV y XV (Hinojosa Montalvo, José: La piratería y el corso en el litoral alicantino a finales de la Edad Media, Alicante, 2004, p. 65).

45. Archivo de la Corona de Aragón (A.C.A.), Consejo de Aragón, leg. ${ }^{\circ} 557$.

46. A.M.M. Ac. Caps. 1636-1637, fol. 137v.

47. A.M.C. Ac. cap. 13-XI-1636; A.M.Mz. Ac. cap. 16-XI-1636; y A.M.L. Ac. cap. 15-XI-1636.

48. A.C.A., C.A., leg. ${ }^{\circ} 557$.

49. A.M.Mz. Ac. Caps. 1631-1637, fol. 245v. 
esas fechas otoñales eran ya muy avanzadas para la navegación en el Mediterráneo, por lo que lo más seguro es que retornasen a sus bases invernales.

\section{EL NAUFRAGIO DE UNA GALERA CORSARIA EN CABO ROIG A FINALES DE MARZO DE 1637 Y SUS POSTERIORES CONSECUENCIAS}

Desde finales de marzo de 1637 merodeaban por la costa alicantina y murciana algunas galeras corsarias en busca de presas fáciles. Por el estado de la mar en esa época del año, se exponían en determinados momentos a las duras inclemencias del tiempo, que en ocasiones excepcionales difícilmente podían sortear. Así les ocurrió el 30 de marzo de ese año a tres de ellas que se vieron sorprendidas por una fuerte tempestad a la altura de cabo Roig. Precisamente la que hacía de «capitana» se vio arrastrada por el mal tiempo hacia la costa y encalló sin poder evitarlo en las inmediaciones de ese cabo. La galera quedó varada en la playa y con numerosos desperfectos, por lo que sus tripulantes - unos 250, según se supo después- saltaron a tierra y huyeron campo a través por las comarcas de Orihuela y Murcia. Alertados los concejos de estas ciudades, se organizó una rápida cacería que permitió capturar a más de 120, entre ellos varios renegados ${ }^{50}$. La búsqueda se prolongó en los días siguientes en los campos de Cartagena, Elche y Alicante. Algunos labradores del campo de Cartagena, armados con arcabuces, consiguieron arrinconar en el Cabezo Gordo a 19 de ellos, que, aunque presentaron batalla, al final se rindieron ${ }^{51}$. También se procedió a evaluar, tanto el contenido de la nave, que fue requisado de inmediato, como el número de tripulantes que perecieron en el naufragio. Pero las autoridades no pudieron evitar que los vecinos de la zona saquearan la galera hundida, ni que se ensañaran con algunos de sus marinos, en especial con su arráez, al que sometieron a un cruel tormento ${ }^{52}$.

Según se supo tras interrogar a algunos de ellos, las galeras habían partido de Argel el 27 de marzo a robar en las costas de Sicilia o España, pero, habiendo estado en la mar tres días sin hacer presa, les sobrevino una noche oscura con mucha niebla que hizo que se perdieran y separaran. La galera embarrancada se había acercado a la costa al ver una luz que centelleaba, creyendo que era un farol, y sin darse cuenta encallaron. De inmediato saltaron todos a tierra y se esparcieron por las comarcas aledañas hasta que fueron apresados.

Tanto el corregidor de Murcia como la Junta Patrimonial de Orihuela coincidieron en que en ella venían 250 turcos, además de 48 esclavos cristianos marineros. De los 250 soldados, 24 de ellos eran renegados (dos de ellos andaluces) y fueron trasladados de inmediato a la Inquisición de Murcia para ser sometidos a interrogatorio. También se supo que la nave estaba artillada con 23 piezas de hierro y dos de bronce ${ }^{53}$. Sin duda, una excelente galera de combate.

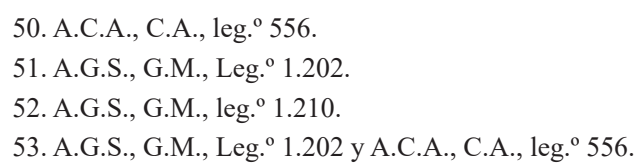


Los turcos o berberiscos capturados fueron identificados uno a uno, interrogados y llevados a prisión. Se procedió al reparto de algunos de ellos entre las autoridades y tropas que habían intervenido en su captura y otros tantos (117 en total) fueron obligados a servir como esclavos al remo en las galeras de España, que se encontraban en Cadaqués, donde fueron entregados el 30 de noviembre de ese año ${ }^{54}$.

El arráez o capitán de la galera, llamado Tareibran, fue detenido por las milicias de Orihuela, las cuales, tomando la justicia por su mano, decidieron llevar a cabo un castigo ejemplar atándole y quemándole, tras haberlo arcabuceado previamente. En ese momento nadie podía imaginar la trascendencia que tendría este crimen, como después veremos en la toma de la torre de Cabo de Palos.

También se obtuvo una valiosa información de los corsarios capturados: en Argel se aprestaban nueve galeras, dos de ellas de nueva construcción, para unirse con las de Bizerta y marchar sobre las costas españolas ${ }^{55}$. La temporada estival de 1637 se preveía bastante intensa y peligrosa, como los hechos posteriores se encargaron de demostrar.

\section{LA TRAGEDIA DE CALPE (1637)}

Pero, antes incluso de la declaración de los turcos del naufragio mencionado anteriormente, ya se conocían en la corte de Felipe IV los hipotéticos planes de los corsarios argelinos para la campaña de 1637. Una carta escrita desde Argel por un cautivo alicantino en enero de ese año informó con enorme precisión sobre las intenciones de aquellos con respecto a las costas de Valencia y Murcia. En ella se rogaba al gobernador de Orihuela y Alicante que se amparara el litoral de ambos reinos «porque en saliendo las galeras de aquí de Arjel, que serán nuebe, lleban la proa a tomar a Calpe y a San Juan». También pedía que se escribiese a la ciudad de Murcia comunicándole esta nueva «porque dicen los moros que se an uydo de Murcia que fácilmente se puede tomar el Maçarrón y Los Alumbres ${ }^{56}$. El aviso del cautivo alicantino fue tramitado por Luis Terrer, teniente de capitán general de Alicante, y llegó hasta el conde de Almenara, que lo puso en conocimiento de las altas autoridades del reino, por lo que los mandatarios valencianos supieron con bastante antelación las intenciones de los marinos berberiscos.

El duro contratiempo de cabo Roig debió disuadir a los corsarios argelinos, los cuales debieron retirarse a Argel. Una vez allí, decidieron cambiar de objetivo, poniendo rumbo a las costas italianas, en donde se ensañaron con algunos pueblos de la ribera de Génova ${ }^{57}$. Allí obtuvieron un suculento botín antes de volver de nuevo a Argel. A finales de julio emprendieron nuevamente la campaña contra las costas del Sureste español.

54. Archivo Naval de Cartagena, libro de esclavos n. ${ }^{\circ} 1$.

55. A.G.S., G.M., Leg. ${ }^{\circ} 1.202$.

56. A.C.A., C.A., leg. ${ }^{\circ} 715$.

57. Biagioni, M.: I corsari barbareschi contro Genova e il Levante ligure, La Spezia, 2001. 
El día 31 de julio fue localizada la escuadra de Alí Bitchín fondeada en la isla de Formentera. Se habían refugiado allí para evitar el furor de los fuertes vientos de levante. Pero fueron descubiertos por los guardas de la isla de Ibiza, que lo comunicaron de forma inmediata a su gobernador. A ello se unió la información aportada por un cautivo que consiguió escapar de una de las galeras y llegar a nado a la isla, donde informó con sumo detalle del objetivo de los corsarios, que no era otro que atacar por sorpresa el pueblo valenciano de Calpe. Según el cautivo, un renegado natural de Alicante, llamado Salvador Mateo, se había ofrecido para guiar por tierra a los argelinos hasta los pueblos de Calpe, Benisa y Teulada con el fin de saquearlos, así como al monasterio de la Santa Verónica de esa ciudad. Señalaba que se trataba de siete galeras y galeotas, de las cuales dos de ellas eran de 28 bancos, con una tripulación total de 1.300 hombres, y que podían poner en tierra entre 700 y 800 soldados. Creía que lo más peligroso era que contaban con escalas muy altas y gruesas por las que podían subir tres hombres a la vez y que no había muralla que se les resistiese. Esta información fue remitida por el gobernador de Ibiza a las autoridades valencianas en un jabeque que tuvo que hacer varias intentonas para salir de la isla forzado por el fuerte viento reinante; jabeque que había logrado partir el día 2 de agosto y del que se suponía llevaba una ventaja de 15 millas sobre las galeotas. Debía llegar a Denia y poner la defensa costera del reino en alerta $^{58}$. Pero, como pudo verse después, o bien no llegó a tiempo o las autoridades no actuaron con la diligencia adecuada.

Sea como fuere, lo cierto es que las siete galeras y galeotas llegaron a las playas de Calpe en la noche del día 2 de agosto y en la madrugada del día siguiente comenzaron a desembarcar su infantería en las proximidades de la villa. Con las escalas que traían subieron las murallas y consiguieron abrir sus puertas.

En este sentido, la información contenida en una carta remitida por el virrey Fernando de Borja a Felipe IV el día 11 de agosto aporta todos los detalles del asalto. En verdad, los corsarios actuaron con tanta cautela que no fueron sentidos por nadie. Se presentaron por sorpresa en dos lugares a la vez: a los pies de la muralla, que remontaron con facilidad gracias a las altas escalas que traían y que les permitieron abrir las puertas, y en el arrabal de la villa, donde encontraron resistencia y se batieron a arcabuzazos con los vecinos. El estallido de la pólvora despertó a todos sus habitantes, que corrieron despavoridos a refugiarse a la torre, mientras que los pocos hombres que quedaban en la villa (unos 23 ó 24) se enfrentaban con los asaltantes, matando a unos treinta e hiriendo a otros setenta. Vencida la resistencia (murieron 16 vecinos y cautivaron a otros 6), los corsarios se encaminaron a la torre, donde forzaron a sus habitantes a que se rindieran. Cuando llegaron los refuerzos de los pueblos próximos -Benisa, Jávea y Teulada- los corsarios ya se habían retirado y sólo encontraron vivos a una mujer y a un hombre. Afortunadamente, una parte importante de la población -unos 45 vecinos- se encontraba fuera de ella ocupada en la recolección de sus cosechas. Pero el

58. A.C.A., C.A., leg. ${ }^{\circ} 715$. 
resto, casi todos mujeres y niños, fueron cautivados ${ }^{59}$. En un primer momento se habló de 296 personas, pero después la cifra fue aumentada hasta $302^{60}$. Todas ellas fueron embarcadas en la galera «patrona», que puso rumbo directo a Argel, mientras que las otras naves tomaron la vía de levante en dirección al pueblo catalán de Cadaqués, que también pretendían asaltar ${ }^{61}$.

La villa de Calpe quedó desolada. Días después volvieron los vecinos que estaban ausentes cuando se produjo el asalto. Eran 65 personas que pudieron comprobar que sus haciendas, sus mujeres y sus niños habían sido cruelmente robados. Sólo disponían de la ropa que llevaban puesta y el peligro al que ahora se enfrentaban, en una villa que había quedado desguarnecida, era enorme. Buscaron la ayuda del virrey para que les suministrara armas con las que defenderse de un nuevo ataque, pero este las ofreció previo pago de su valor. Viendo la inutilidad de su súplica, decidieron elevar su petición al rey el 26 de agosto, de la cual desconocemos si finalmente surtió efecto ${ }^{62}$.

De todas formas, las autoridades del reino tomaron algunas medidas rápidas: por un lado, decidieron reforzar todas las defensas de la costa, con suministro abundante de pólvora y munición, asistencia de las milicias, visita de las torres y aumento de las dotaciones; por otro, también se llevó a cabo una investigación sobre los hechos que demostró que algunas de las guardas no estaban en su sitio en el momento de la invasión, pero también se hizo notar que la falta de soldados en aquellos lugares se debía en parte al traslado de algunas compañías de caballos a Navarra ${ }^{63}$.

Las otras diligencias llevadas a cabo por las autoridades se orientaron a recaudar en el menor tiempo posible el dinero suficiente para organizar el rescate de los cautivos, pues se pensaba que las galeotas, que permanecían fondeadas en el puerto de Moraira, habían propuesto alafia de los cautivos ${ }^{64}$. La conmoción provocada por el asalto a Calpe provocó la compasión general de todos habitantes del reino, y más aún cuando se temía que por ser los cautivos en su mayoría niños y mujeres, renegarían con facilidad de la religión católica. Las cantidades ofrecidas por las diferentes instituciones y particulares fue la siguiente: el arzobispo, 40.000 reales, el cabildo de la iglesia Mayor más de 20.000 reales, la ciudad 10.000 reales, la casa de la Generalidad 10.000 reales, la religión de la merced 15.000 reales, los inquisidores -a título particular1.500 reales, y finalmente, la limosna recogida por las parroquias y el clero ascendió a

59. A.C.A., C.A., leg. ${ }^{\circ} 715$ y 879.

60. A.C.A., C.A., leg. ${ }^{\circ} 879$.

61. A.G.S., G.M., Leg. ${ }^{\circ} 1.200$.

62. A.C.A., C.A., leg. ${ }^{\circ} 879$.

63. Requena Amoraga, Francisco: El corso turco-berberisco..., pp. 359-360.

64. A.C.A., Consejo de Aragón, leg. ${ }^{\circ}$ 715. Las alafias o rescate directo de cautivos en la misma costa fue una práctica muy común en el Mediterráneo español (ANDúJAR CASTILlo, Francisco: «Los rescates de cautivos en las dos orillas del Mediterráneo y en el mar (alafias) en el siglo XVI», Le commerce des captifs: les intermédiaires dans l'echange ete le rechat des prisioners en Mediterranée, XVe-XVIIIe siècle, Roma, 2008, pp. 135-164) 
unos 3.000 ducados $^{65}$. Pero las galeotas acabaron marchando y la posible negociación no pudo llevarse a cabo. En los meses siguientes hubo diferentes intentos sin éxito para rescatarlos. Algunos de ellos fueron redimidos a partir de 1642 mediante el pago de una fuerte suma de dinero en oro y el canje por otros esclavos berberiscos del reino de Valencia, pero hasta 1646 no lograron retornar los últimos cautivos de Calpe.

\section{LA VENGANZA SOBRE CABO DE PALOS Y LAS TORRES MURCIANAS DE LA MANGA}

Las noticias sobre el ataque a Calpe y el posterior cautiverio de su población causaron un tremendo impacto en las poblaciones litorales de los reinos de Valencia y Murcia. En Cartagena fueron prevenidos los soldados de las compañías, se pusieron 25 hombres en los puestos principales de vigilancia, se duplicaron las postas dentro de las murallas, se enviaron los sobreguardas a reconocer la costa y se informó de la noticia de Calpe al alcaide del castillo, a los oficiales de las torres costeras, al capitán de artillería, a la villa de Mazarrón y al corregidor ${ }^{66}$. En verdad, se temía que los corsarios pudiesen llevar a cabo un asalto a Cartagena a las dos de la mañana, y no andaban muy lejos de lo cierto, pues ese mismo día 7 hubo que convocar un cabildo extraordinario a las 11 de la noche al descubrir un atalayero siete galeras. Pero la noche pasó sin mayor novedad, y en los días siguientes, las galeras que habían sido avistadas el 7 de agosto, dejaron de hacer acto de presencia, aunque la ciudad quedó prevenida, manteniendo enarboladas las banderas de las compañías y en estado de alerta las torres y atalayas de la costa.

Referíamos anteriormente cómo las galeras tomaron rumbo hacia Cadaqués, pero un fuerte levante las desvió de su ruta y se vieron forzadas a trasladarse a las costas de Berbería, donde fondearon y despalmaron cerca de la Torre Vieja (situada a 20 leguas a poniente de Orán). Desde allí partieron en dirección a las costas andaluzas, con la intención de asaltar Estepona o Marbella, pero de nuevo otro viento en contra las desvió de su objetivo. Decidieron entonces tomar Nerja, pero no pudieron lograrlo, al igual que el castillo de Roquetas de Mar, ya que, avisados sus guardas, encendieron muchas hogueras en demanda de socorro. Esto disuadió a los corsarios, los cuales decidieron continuar su viaje hasta el cabo de Gata. Allí desembarcaron a un cautivo de Cartagena, cuya declaración sirvió para conocer con detalle el periplo de estas galeras, al frente de las cuales estaba el temido Alí Bitchín ${ }^{67}$.

No tardaron en aparecer estas naves en la costa murciana. A las 6 de la tarde del 21 de agosto fueron divisadas desde la bocana del puerto de Cartagena las seis galeras que habían protagonizado los trágicos hechos de Calpe. En el cabildo extraordinario del día siguiente se presentó uno de los soldados de la compañía acantonada en Alumbres y confirmó que había divisado personalmente cómo las citadas galeotas estaban fon-

65. A.C.A., C.A., leg. ${ }^{0} 556$.

66. A.M.C. Ac. Caps. 1635-1637, fol. 464 v.

67. A.G.S., G.M., Leg. ${ }^{\circ} 1.200$. 
deadas frente al cabo de Palos, desde donde cañoneaban su torre. Inmediatamente, uno de los regidores del concejo, Sancho de Sepúlveda, visitador de las torres de la costa, solicitó al ayuntamiento y al corregidor que se organizase un socorro para los hombres que servían en la torre de Cabo de Palos ${ }^{68}$.

Los regidores propusieron enviar una compañía con 200 infantes con las municiones necesarias para tres días, a los que se añadirían cuantos otros hombres quisieran ir voluntarios (se formó otra compañía más). Mientras, los corsarios hacían su trabajo destructivo sobre las pequeñas fortalezas del Mar Menor. Primero acometieron la torre de Cabo de Palos, para dar cuenta posteriormente de las de El Estacio, La Encañizada y Pinatar. Al día siguiente, 23 de agosto, se leía en el ayuntamiento una carta de los dos capitanes que habían ido a socorrer la torre de Cabo de Palos en la que señalaban que había sido tomada por los moros, los cuales la habían incendiado después de capturar a sus defensores. Aseguraban también que se encontraba ardiendo desde la tarde anterior y que, en el momento en el que escribían la carta, esas seis galeras se marchaban en dirección a la torre de El Estacio.

La ciudad de Murcia también intervino, aunque más lentamente, en defensa de sus torres. La actuación murciana se inicia el 22 de agosto, cuando su concejo decidió en sesión extraordinaria enviar las dos compañías de la milicia hacia Cartagena y el Mar Menor.

Pero, como puede comprobarse, las medidas tomadas, tanto por los concejos de Cartagena y Murcia como por el mismo corregidor, llegaron demasiado tarde y nada se pudo hacer para salvar las guarniciones y las propias torres de Cabo de Palos, El Estacio, La Encañizada y Pinatar. Los corsarios actuaron con la máxima contundencia y algunos de estos baluartes fueron literalmente arrasados. Pero se cebaron en especial con la dotación de Cabo de Palos, pues su alcaide fue maniatado, arcabuceado y quemado ${ }^{69}$.

La enorme virulencia con la que se emplearon los corsarios argelinos en Cabo de Palos llamó poderosamente la atención de los primeros soldados que llegaron a la torre, una vez abandonada por sus sitiadores. En una larga carta enviada por el corregidor al rey, escrita el 24 de agosto, explicaba con detalle lo que había presenciado in situ el visitador de las torres Sancho González de Sepúlveda: «la alló quemándose, lleuada la artillería, muerto el alcaide y medio quemado con la cureña de las dos pieças que allí auia, y a los pies de la torre un papel, que pareze dejaron los moros... y dan a entender que lo que azen es irritación de lo que içieron los días pasados en Origuela con el capitán del navío de moros que en aquella marina embarrancó, que teniéndolo rendido y maniatado lo arcabuçearon y quemaron...» ${ }^{70}$.

68. A.M.C. Ac. caps. 22-VIII-1637.

69. RuIz IвÁÑEz, José Javier: Las dos caras de Jano. Monarquía, ciudad e individuo. Murcia, 1588-1648, Murcia, 1995, p. 63.

70. A.G.S., G.M., leg. ${ }^{\circ} 1.210$. 
La carta a la que hacía mención alude a las leyes de la «buena guerra», que -según los corsarios argelinos- los españoles se habían saltado, empleándose con extrema violencia sobre el capitán de la embarcación corsaria, al que habían maniatado, arcabuceado y quemado pese a haberse rendido con antelación. El citado escrito se expresaba en los siguientes términos: «En el nombre de Dios. Esta será para hacer sauer como con la ayuda de Dios emos tomado esta torre de Cauo de Palo y en ello emos tomado tres cristianos y uno muerto, y lo quemamos por auer tomado nuebas del vagel que se perdió en Alicante, que quemaste Vs. Ms. el capitán después de auerle muerto, y de aquí adelante todos los que murieren españoles castellanos todos yran por esse camino, pues que Vs.Ms. an començado y no es de ombres lo que an echo, sino buena paz y buena guerra dize el refrán ${ }^{71}$.

Sea como fuere, lo cierto es que las torres de Cabo de Palos y de la Manga del Mar Menor soportaron toda la ira y venganza de los corsarios argelinos, posiblemente soliviantados por la pérdida de algún familiar o amigo en el naufragio de Cabo Roig. Por parte cristiana, la torpeza del corregidor, que no supo valorar bien la envergadura de la amenaza corsaria, y la lentitud institucional del concejo murciano, provocaron que los refuerzos de la capital llegaran con demasiado retraso a sus torres del Mar Menor (El Estacio, La Encañizada y Pinatar), pues no fue hasta el 28 de agosto cuando acordaron enviar dos escuadras de 30 soldados para defender las citadas torres ${ }^{72}$. Es evidente que cuando llegaron estos 60 soldados a las inmediaciones del Mar Menor hacía más de cuatro días que las torres de El Estacio y La Encañizada estaban destruidas en parte, su guarnición apresada y su escasa artillería desaparecida.

No pudieron hacer mucho más estos refuerzos que certificar la marcha de los corsarios hacia otros destinos, por lo que a primeros de septiembre se ordenó su retorno a Murcia y Cartagena. Pero la tranquilidad duró poco, puesto que las siete galeotas volvieron a aparecer el día 3 de octubre en la isla Grosa y provocaron otra situación de máxima alerta. En este caso, Cartagena envío dos compañías - una a levante y otra a poniente- para impedir nuevos desembarcos, y Murcia hizo lo propio con una tropa de 70 soldados al mando del capitán Aliaga, que fueron apostados en la torre de La Encañizada, donde permanecieron casi un mes custodiando las torres ${ }^{73}$.

\section{LA DESASTRE NAVAL DE VALONA Y LA RUINA DE LA ARMADA DE REMO BERBERISCA (1638)}

Ya a comienzos de enero de 1638 llegaron a Cartagena avisos de Argel alertando sobre la preparación de diez galeotas en su puerto. Se presumía un verano muy caliente y más cuando se supo en mayo que eran once las galeras y galeotas argelinas y que aguardaban la llegada de las naves de Bizerta para unirse a ellas ${ }^{74}$. No tardaron en con-

71. Ruiz IbÁÑez, José Javier: Las dos caras..., p. 63.

72. A.M.M. Ac. caps. 28-VIII-1637.

73. A.M.M. Ac. cap. 31-10-1637.

74. A.M.C. Ac. cap. 18-V-1638. 
firmarse los peores augurios y a final de ese mes aparecieron las dos primeras galeotas en cabo Tiñoso. Se determinó despachar a dos compañías: una para proteger la torre de La Azohía y los caseríos de poniente, y la otra para guarecer el pueblo de Alumbres y las calas y surgideros de levante ${ }^{75}$.

Fue un pequeño susto, nada comparable con el fuerte rebato que provocaron las diecinueve galeras de las armadas de Argel y Túnez que se presentaron a la vista del puerto cartagenero el 13 de junio. Daba la casualidad de que en ese momento se encontraban dentro de su ensenada las diez galeras de la escuadra de Génova, mandadas por Juanetín Doria, y de que en Alicante se hallaba la armada holandesa con veintiséis navíos, lo que debió de disuadir a la fuerza corsaria, que tomó dirección hacia Guardamar y de allí hacia las costas africanas ${ }^{76}$.

En Argel recibieron la orden del sultán de Constantinopla para que intervinieran, como vasallos del imperio turco, en la campaña de castigo que preparaba contra Venecia. Pero antes la escuadra de remos combinada de Argel y Túnez se dejó ver una vez más por las costas del Sureste. A primeros de agosto fueron divisadas 18 galeras berberiscas a la altura de Mazarrón y poco después en Vera y Mojácar. Más tarde debieron de llegar a Argel, donde se reagruparon antes de partir para la costa adriática $^{77}$.

Bajo la dirección de Alí Bitchín, una veintena de galeras berberiscas pusieron rumbo desde La Goleta hacia el Adriático. Una parte importante de ellas eran propiedad del propio Bitchín, gran almirante de Argel, y otras procedían de Bizerta (Túnez). Comenzaron emprendiendo varias razias sobre las costas adriáticas, sobre todo en Calabria $^{78}$. A consecuencia de estos ataques, varios barcos mercantes venecianos fueron capturados, lo que provocó el enfado inmediato de la Señoría, que consideraba estos actos como hostiles, y decidió tomar medidas enérgicas de represalia. Rápidamente se ordenó la salida de la armada veneciana compuesta por 28 galeras y dos galeazas, comandada por el almirante Capello, hacia las costas de Albania donde los navíos argelinos habían sido descubiertos ${ }^{79}$.

La flota berberisca, a consecuencia de una tempestad, se refugió en el pequeño puerto de Valona (Vlora, actual Albania) y permaneció allí más de lo razonable bajo el amparo de los cañones turcos de su fortaleza. Pero Capello, que en un principio se había limitado a una acción de bloqueo sobre el puerto, enterado de que llegaba una escuadra en auxilio de los berberiscos, decidió atacar tanto la fortaleza como a las galeras corsarias. La fortaleza fue cañoneada por las galeazas, mientras que sus galeras asaltaban una a una las naves musulmanas. El éxito fue rotundo: unos 1.500 turcos muertos, 3.500 cristianos liberados, 12 galeras y dos bergantines capturados y 4

75. A.M.C. Ac. cap. 31-V-1638.

76. A.M.C. Ac. caps. 13, 16 y 20-VI-1638.

77. A.M.L. Ac. cap. 7-VIII-1637 y A.M.Mz. Ac. cap. 13-VIII-1637.

78. Tinninswood, Adrian: Pirates of Barbary..., pp. 145-146.

79. LANE, Frederic C.: Storia di Venezia, Torino, 1991, p. 472. 
galeotas hundidas. Bitchín logró escaparse con alguna galera, pero todo lo demás fue destruido ${ }^{80}$.

La derrota de Valona además de ser un gran desastre personal para Alí Bitchín, supuso una derrota moral para los turcos. Debemos de tener en cuenta que políticamente la regencia de Argel era un estado vasallo del imperio turco y que Valona era una posesión otomana. Por eso los efectos del bombardeo, que destruyó numerosas casas y la mitad de una mezquita, sin contar las grandes pérdidas humanas en su población, además de la humillación de la armada berberisca, provocó el enfado del sultán. Desde entonces, las relaciones entre la Sublime Puerta y la Serenísima República se envenenaron muy seriamente y Valona estuvo a punto de constituir un casus belli entre las dos potencias. Afortunadamente para Venecia, el imperio otomano estaba inmerso en una difícil guerra contra Persia y estimó imprudente en ese momento lanzarse simultáneamente a otro conflicto ${ }^{81}$.

\section{VUELVE LA CALMA (1639-1640)}

Alí Bitchín quedó muy tocado después de la derrota de Valona, pues habían sido destruidas la mayor parte de sus galeotas. Descontento con lo sucedido, Bitchín comenzó a apoyar revueltas contra el poder del sultán en la regencia de Argel. Le reprochaba, apoyado por los arráeces, el haber expuesto sus personas y sus bienes en unas guerras donde ellos no podían sacar ningún provecho y el no haberlos indemnizado de sus pérdidas. Desde entonces las relaciones entre los armadores y corsarios argelinos con la Sublime Puerta quedaron más enrarecidas que nunca ${ }^{82}$ y a la postre, como vimos al principio, provocarían la caída de Bitchín, posiblemente asesinado.

De lo dicho hasta aquí, se puede entender cómo a partir de Valona la presencia de galeotas en el Sureste español se redujo a la mínima expresión. De hecho, pasó un año largo hasta que volvió aparecer otra nave de remos, nave que fue descubierta en la costa de levante de Cartagena el 17 de octubre de 1639 y recaló en la isla Grosa en los días siguientes acompañada de un bergantín. Como en otras ocasiones, el concejo cartagenero envío dos compañías para intentar una emboscada contra los corsarios, pero no parece que tuviera mucho éxito ${ }^{83}$.

La calma había vuelto a las costas de Alicante y Murcia después de los devastadores años de 1635 a 1638 . Argel se había quedado sin galeras por el momento, como señalaba un acta capitular del concejo murciano: «y a esto se allega nuevas de galeras, que aunque no las tenía Argel, bienen de Constantinopla algunas, con ánimo de pasar a estas costas, y ya emos tenido en ellas tres días una en la ysla Grosa» ${ }^{84}$.

80. Wolf, John B.: The Barbary Coast..., 1979, pp. 209-210.

81. Lane, Frederic C.: Storia..., p. 472.

82. Tinninswood, Adrian: Pirates of Barbary..., pp. 188-190.

83. A.M.C. Ac. caps. 17 y 20-X-1639.

84. A.M.M. Ac. cap. 22-X-1639. 
$\mathrm{Y}$ en efecto, la escuadra de remo de Argel fue repuesta con algunas galeras procedentes de Estambul, que comenzaron a deambular por los mares del Sureste en los meses de mayo (Santa Pola), julio (Mazarrón), agosto (cinco galeotas en Mazarrón), septiembre (dos en Cartagena) y octubre (cuatro en isla Grosa) de $1640^{85}$, pero ya no ofrecieron el peligro y la intimidación que las escuadras aparecidas en los años centrales de esta década.

\section{CONCLUSIONES}

Como hemos podido ver a lo largo de estas páginas, a pesar del éxito fulgurante de los navíos de alto bordo dentro del corso berberisco desde la década de 1610, las viejas galeras y galeotas, tan predominantes en el siglo XVI, no llegaron a desaparecer del todo. Antes al contrario, recibieron un nuevo impulso con el nombramiento de Alí Bitchín como jefe de la taifa de arráeces de Argel. Alí Bitchín fue, con diferencia, el hombre más rico y poderoso del Argel de 1630, y gran parte de su fortuna se la debía al tráfico de los esclavos que capturaba en las costas españolas e italianas.

También hemos comprobado cómo solía encabezar estas razias anuales, gobernando las escuadras de Argel y Túnez y atacando a los pequeños buques mercantes (saetías, fragatas, tartanas, etc.) e incluso otros de mayor tonelaje (urcas, polacras). Asimismo, tuvo como objetivo preferente el asalto de los pequeños pueblos litorales y la destrucción de la red de torres de defensa construidas durante el siglo XVI.

Sin duda, uno de los espacios litorales más castigados por estas galeras, junto a las costas del Mezzogiorno italino y las islas (Córcega, Cerdeña y Baleares), fue el Sureste español (las andaluzas, aunque también las sufrieron, estuvieron más a merced de Tetuán o Salé), dada su proximidad a los grandes focos corsarios de Túnez y Argel y al desarrollo comercial que vivían sus principales puertos. Y aunque sus ataques a las marinas de Alicante y Murcia ya se iniciaron en los primeros años de la década de 1620 , realmente fue a partir de 1631 cuando éstas se convirtieron en un objetivo prioritario para sus diferentes campañas anuales.

De este modo, el número de desembarcos en tierra y de abordajes de embarcaciones desde sus guaridas en Cope, isla Grosa e isla de Santa Pola comenzó a ser alarmante desde 1633; e incluso, a partir de 1635, añadieron además una nueva estrategia dirigida a destruir sus torres costeras. En este sentido, fueron saqueadas y casi destruidas la mayor parte de las torres murcianas (Águilas, Cabo de Palos, El Estacio, La Encañizada y Pinatar) y de la marina de Orihuela (Torrevieja, Cabo Roig y La Horadada), con un claro propósito de capturar a sus defensores y desproteger aún más estas castigadas costas.

Pero el punto culminante de esta escalada de terror se alcanzó con el asalto por sorpresa a la villa de Calpe, donde fueron capturados 302 de sus habitantes -sobre todo mujeres y niños-y perecieron una veintena de vecinos. Calpe demostró no sólo

85. Requena Amoraga, Francisco: El corso turco-berberisco..., p. 371, A.M.Mz. Ac. cap. 8-VII y 20-VIII1640 y A.M.C. Ac. caps. 20-IX y 3-X-1640. 
lo indefensas y vulnerables que eran las localidades costeras de ambos reinos ante las acometidas de las galeras berberiscas, sino, sobre todo, la poca capacidad que las armadas del rey católico tenían para controlar la seguridad de sus mares en un momento en el que el corso berberisco alcanzaba uno de sus puntos culminantes (alargando mucho más allá de 1620 la segunda etapa dorada de la que hablaba Braudel).

Afortunadamente para este espacio litoral, la implicación de la fuerza de remo berberisca en el enfrentamiento que el sultán turco mantenía con Venecia, con el consiguiente desastre de Valona (Albania), provocó la pérdida de la mayoría de estas naves, con lo que el Sureste pudo recobrar una relativa calma a partir de 1639, ya que solo una pequeña parte de ellas pudo ser repuesta posteriormente. 